J. Lake Sci. (湖泊科学), 2011, 23(1): 136-142

http: //www.jlakes.org. E-mail: jlakes@niglas.ac.cn

(C) 2011 by Journal of Lake Sciences

\title{
鄱阳湖湿地生态功能重要性分区*
}

谢冬明 ${ }^{1,2,3,4}$, 邓红兵 ${ }^{4 * *}$, 王丹寅 ${ }^{1,4}$, 田 野 $^{4,5}$

(1: 中国科学院城市环境研究所,厦门 361012)

(2: 江西省遥感信息系统中心 , 南昌 330046)

(3: 江西省山江湖开发治理委员会办公室,南昌 330046)

(4:中国科学院生态环境研究中心城市与区域国家重点实验室,北京 100085)

(5: 中国科学院新疆生态与地理研究所, 乌鲁木齐 830011$)$

摘 要: 在分析鄱阳湖湿地自然环境特征和湿地生态系统服务功能特征基础上, 利用 GIS 技术, 对鄱阳湖湿地范围进行 界定, 湿地面积为 $3886 \mathrm{~km}^{2}$. 基于湿地生态环境保护和社会经济发展总体要求, 按照生态功能区划原理, 对湿地进行生态 功能重要性分区研究. 根据湿地生态功能重要性评价结果将湿地分为极重要区、高度重要区、重要区、一般重要区四个区 域,其面积分别是 $125 \mathrm{~km}^{2}, 1387 \mathrm{~km}^{2}, 2064 \mathrm{~km}^{2}$ 和 $310 \mathrm{~km}^{2}$. 针对分区结果, 文中提出了湿地生态保护对策与建议.

关键词: 湿地生态功能; 重要性分区; 鄱阳湖

\section{Zoning of ecological function importance for Lake Poyang wetlands}

\author{
XIE Dongming ${ }^{1,2,3,4}$, DENG Hongbing ${ }^{4}$, WANG Danyin ${ }^{1,4} \&$ TIAN Ye ${ }^{4,5}$ \\ (1: Institute of Urban Environment, Chinese Academy of Sciences, Xiamen 361012, P. R. China) \\ (2: Centre for RS\& GIS of Jiangxi Province, Nanchang 330046, P. R. China) \\ (3: Office of MRL Development Committee of Jiangxi Province, Nanchang 330046, P. R. China) \\ ( 4 : State Key Laboratory of Urban and Regional Ecology, Research Center for Eco-Environment Science, Chinese Academy of \\ Sciences, Beijing 100085 , P. R. China) \\ (5: Xinjiang Institute of Ecology and Geography, Chinese Academy of Sciences, Urumqi 830011, P. R. China)
}

Abstract: The boundary of wetlands of Lake Poyang was analyzed with RS and GIS tools based on the natural environment and ecological function. The area of wetlands was $3886 \mathrm{~km}^{2}$. The importance of ecological function was appraised based eco-environmental protection and social-economic development according to the theory of ecological function regionalization. According to the result of ecological function importance appraising, the wetlands could be divided into four zones as vital important zone, high degree important zone, important zone, and general important zone, with areas of $125 \mathrm{~km}^{2}, 1387 \mathrm{~km}^{2}, 2064 \mathrm{~km}^{2}$ and $310 \mathrm{~km}^{2}$, respectively. Some suggestions and countermeasures for wetlands protection were also put forward.

Keywords: Wetlands ecological function; importance zoning; Lake Poyang

湿地是介于水陆之间生物多样性非常丰富的区域, 其生态环境相当脆弱 ${ }^{[1]}$. 由于全球人类及经济迅速 发展的过程中长期忽视地球环境的保护, 地球生态环境日益恶化, 湿地丧失和功能退化成为突出的问题之 ${ }^{[2]}$, 由此所带来的生态环境影响自然成为人类关注的热点 ${ }^{[3]}$. 鉴于湿地重要的生物多样性和水文功能, 各 国政府和国际社会普遍把湿地的退化和丧失视为严重的生态环境问题,湿地已成为环境政策的优先点 ${ }^{[4]}$.

空间分区研究是地理学的古老传统,也是地理学的永恒主题. 区域空间功能分区, 是自然地理空间微观 尺度上的地理分异性特征的研究, 其目标是区域空间多功能性的充分利用和保护. 在自然地域系统中, 湿地

* 江西省鄱阳湖生态经济区重大招标课题项目 (08ZD501) 和国家科技支撑计划重点项目 (2007BAC23B05) 联合资助. 2010-01-07 收稿;2010-06-17 收修改稿. 谢冬明,男,1977 年生,博士,助理研究员; E-mail:xdm0791@ 126. com.

** 通讯作者;E-mail: denghb@ rcees. ac. cn. 
是一种区域自然地理空间类型. 在自然地理空间特征上,湿地具有一定的特殊性,例如,在以气候为基础的 区划体系中,湿地表现出非地带性特征 ${ }^{[1]}$.

鄱阳湖是中国最大的淡水湖泊, 鄱阳湖湿地是中国第一批加人拉姆萨尔湿地公约的湿地, 是国际重要 湿地. 国务院于 2009 年 12 月 12 日批准《鄱阳湖生态经济区建设规划》, 鄱阳湖更加受到广泛关注. 鄱阳湖 湿地具有许多功能和价值,包括调节水源、防洪蓄洪、有机物质生产、保护土壤功能、 $\mathrm{CO}_{2}$ 固定和 $\mathrm{O}_{2}$ 释放、降 解污染、科研和文化价值等, 其生态系统服务功能价值每年达 $1381.01 \times 10^{8}$ 元 $^{[5-6]}$. 近年来, 随着经济发展和 资源过度开发,各种因素严重影响着鄱阳湖湿地的演变,破坏了湿地生态系统平衡, 导致湿地生物多样性的 减少, 鄱阳湖湿地生态环境的脆弱性进一步加剧 ${ }^{[7]}$. 进行鄱阳湖湿地生态功能重要性分区研究,有利于鄱阳 湖岸线保护和控制的规划 ${ }^{[8]}$, 有利于指导鄱阳湖湿地的生态保护与建设、自然资源有序开发和产业合理布 局,推动鄱阳湖生态经济区的经济社会与生态保护协调、健康发展.

\section{1 研究区概况}

鄱阳湖 $\left(28^{\circ} 22^{\prime}-29^{\circ} 45^{\prime} \mathrm{N}, 115^{\circ} 47^{\prime}-116^{\circ} 45^{\prime} \mathrm{E}\right)$ 地处江西省的北部, 长江中下游南岸, 鄱阳湖在古代有过 彭䔄湖、彭意泽、彭泽、彭湖、扬澜、宫亭湖等多种称谓 ${ }^{[9-10]}$. 鄱阳湖属亚热带湿润季风型气候, 受西伯利亚寒 流和副热带高压影响, 鄱阳湖冬春寒、夏多雨、秋旱特征. 鄱阳湖是鄱阳湖流域的聚水区, 流域面积 $16.22 \times$ $10^{4} \mathrm{~km}^{2}$, 占江西省流域面积 $97 \%$, 流域内的赣江、抚河、信江、饶河、修河五大河流经鄱阳湖, 然后进人长江, 鄱阳湖历史上最大水域面积超过 $5000 \mathrm{~km}^{2[11]}$. 鄱阳湖是一个季节性湖泊, 鄱阳湖水位 (湖口水位, 吴淞高程, 下同) 变化非常显著,年内变幅超过 $10 \mathrm{~m}$,年际间最大变幅达 $16.69 \mathrm{~m}^{[12]}$, 高水是湖、低水似河.

翻阳湖周边分布着 10 个县市,包括南昌县、进贤县、余干县、鄱阳县、都昌县、湖口县、九江市、星子县、 永修县、新建县等, 2006 年人口 640.8 万人, 人口密度为 371 人 $/ \mathrm{km}^{2}$, 是鄱阳湖流域人口密度最高的区域. 2006 年 GDP 为 758.8 亿元, 人均 GDP 为 11841.4 元, 是流域人均生产总值较高的区域.

\section{2 数据与研究方法}

\section{1 数据来源}

(1) 水位数据: 水位数据由江西省水文局提供, 时间尺度为 $1951-2005$ 年的月平均水位数据,包括湖口 站和星子站两个水文站点.

(2) DEM 源数据:DEM 源数据包括等高线数据和高程点数据, 数据精度为 $1: 50000$, 数据源于江西省测 绘局.

(3) 专题地图数据: 专题地图数据包括土地利用数据 (1:100000)、植被数据 (1:100000)、交通道路数据 (1:400000)、鱼类资源空间分布数据 $(1: 100000)$ 、钉螺分布数据 $(1: 400000)$ 、候鸟分布数据 $(1: 400000)$ 等, 数据源于江西省各部门.

(4) 社会经济数据:社会经济数据主要引用《江西统计年鉴》和鄱阳湖周边县市的《年鉴》数据,数据源 于江西省统计部门.

(5) 遥感影像数据: 遥感影像数据主要是来自美国 Landsat 系列数据, 包括 Landsat3,4,5 TM 和 Landsat7 ETM 遥感影像, 数据分辨率为 $30 \mathrm{~m}$.

\section{2 研究方法}

2.2.1 技术方法 分区单元划分方法按照“自下而上”的聚类法. 通过构建评价指标体系,在分析鄱阳湖湿 地自然环境特征和湿地生态系统服务功能特征基础上,将湿地按照生态功能重要性划分为极重要区、高度 重要区、重要区、一般重要区四个等级,每个等级依次赋值为 $10 、 7 、 4 、 1$. 在 Arcgis 软件系统中, 按照栅格分析 原理,进行叠加运算, 得出鄱阳湖湿地自然环境生态功能重要性评价结果和湿地生态系统服务功能重要性 评价结果, 将两者叠加, 得出鄱阳湖湿地生态功能重要性分区评价结果.

2.2.2 评价指标 湿地生态功能分区指标是进行湿地生态功能分区的基础,指标体系的选择要求简单易得 和避免指标信息覆盖不全和指标间信息重叠,选取关键性因素用于评价 ${ }^{[13]}$. 根据鄱阳湖湿地自然景观特征 和生态系统服务功能特征, 本文选取以下指标进行评价. 
（1）自然环境指标. 自然环境指标主要是指湿地自然生态环境特征及分异规律, 是湿地自然属性的外 在表现. 本文选取的自然环境指标包括人类活动干扰指数、水生植被指数、感染钉螺密度指数、水质敏感指 数和湿地裸露指数.

(1) 人类活动干扰指数 (Human Interference Index, HII). 指人类对鄱阳湖湿地可能造成的干扰现象. 以鄱 阳湖湿地某一点到湿地边界最短距离 (单位: $\mathrm{km}$ ) 计算, 距离边界较近的湿地, 人类活动干扰指数就越高, 距 离湿地边界越远, 人类活动干扰指数越小.

(2) 水生植被指数 (Aquatic Vegetation Index,AVI). 本文所指的水生植被包括挺水、浮水和草洲植被,采 用盖度表示湿地水生植被状况.

(3) 感染钉螺密度指数 (Infected Oncomelania Density Index, IODI). 指湿地区域感染血吸虫钉螺的密度, 单位只 $/ \mathrm{m}^{2}$.

(4. 水质敏感指数 (Water Sensitivity Index, WSI). 鄱阳湖是鄱阳湖流域聚水区, 接纳了流域排放的所有物 质,这些物质类型多样,如有机质、氨氮、总磷、重金属等,这些物质在一定程度上会造成鄱阳湖水质的污染. 本文提出水质敏感指数, 主要是考虑鄱阳湖的污染物主要来自鄱阳湖流域的各个河流,根据各条河流进人 湖泊的污染物量, 评价鄱阳湖水质受到污染的可能性. 距离河口越近, 其水质受到污染的可能性越高. 计算 方法以离河口的距离表示, 距离河口越远, 其重要性越明显,单位 $\mathrm{km}$.

(5) 湿地裸露指数 (Wetland Exposure Index, WEI). 指湿地裸露的天数, 根据裸露天数的多少划分不同的 等级.

表 1 鄱阳湖湿地自然环境评价指标

Tab. 1 Indicators for natural environment appraised in Lake Poyang wetlands

\begin{tabular}{|c|c|c|c|c|c|}
\hline 分级 & 极重要区 & 高度重要区 & 重要区 & 一般重要区 & \\
\hline $\begin{array}{l}\text { 人类活动干扰指数 } \\
(\mathrm{km})\end{array}$ & $>5.0$ & $5.0-2.0$ & $2.0-0.5$ & $<0.5$ & $\begin{array}{l}\text { 以湿地边 } \\
\text { 界作缓冲 }\end{array}$ \\
\hline 水生植被指数 & $>50$ & $50-30$ & $5-20$ & 裸地和水体 & 植被盖度 \\
\hline 感染钉螺密度或活螺 & 感染钉螺 & 感染钉螺密度 < 0.045 & 无螺或无感染螺且活螺 & 滩涂、裸地 & \\
\hline 密度指数(只/m²) & 密度 >0.045 & 或活螺密度 > 18 & 密度 $<18$ 的草洲和沼泽地 & 和岛屿 & \\
\hline 水质敏感指数( km) & $>20$ & $20-10$ & $10-3$ & $<3$ & $\begin{array}{l}\text { 以五大河流 } \\
\text { 人湖口缓冲 }\end{array}$ \\
\hline 湿地裸露指数 (d) & $<30$ & $169.5-30$ & $271.5-169.5$ & $>271.5$ & \\
\hline 分级赋值( C) & 10 & 7 & 4 & 1 & \\
\hline
\end{tabular}

通过下面方法计算鄱阳湖湿地自然环境指标的重要值:

$$
S S_{j}=5 \sqrt{\prod_{i=1}^{5} C_{i}}
$$

式中, $S S_{j}$ 为鄱阳湖湿地自然环境指标的重要值, $C_{i}$ 为影响湿地自然环境指标的等级值. 利用地理信息 系统软件中的空间叠加分析功能, 把人类活动干扰指数、水生植被指数、感染钉螺密度指数、水质敏感 指数、湿地裸露指数 5 个单因子自然环境的图层叠加, 计算每一个空间单元 $(10 \mathrm{~m} \times 10 \mathrm{~m}$ 栅格 $)$ 的自然 环境指数.

(2) 生态系统服务功能重要性指标. 湿地具有重要的生态系统服务功能 ${ }^{[14]}$. 本文在综合分析鄱阳湖 湿地自然特征的基础上, 着重考虑鄱阳湖湿地生态多样性保护和产品提供两个方面的服务功能, 即候鸟 保护重要性指数、鱼类资源保护重要性指数、旅游资源潜力指数、水产养殖发展指数和饮用水源地重要性 指数.

(1) 候鸟保护重要性指数 (Migratory Birds Protection Significance Index, MBPSI). 鄱阳湖湿地是国际候鸟 保护重要区域, 由于全球主要白鹤在这里越冬, 白鹤保护的作用最为明显. 评价候鸟保护重要性指数采用候 乌分布密度表示. 
(2) 鱼类资源保护重要性指数 (Fish Protection Significance Index, FPSI). 鄱阳湖湿地鱼类资源非常丰富, 经济鱼类和保护鱼类资源广泛分布. 评价鱼类资源保护重要性指数由鱼类分布密度及鱼类的保护价值 决定.

(3) 旅游资源潜力指数 (Tourism Potentiality Index, TPI). 鄱阳湖湿地是长江流域一颗璀骤的明珠, 作为中 国最大的淡水湖泊, 特别是丰富的鸟类资源, 每年吸引众多游客到鄱阳湖湿地旅游观光. 评价旅游资源潜力 指数由鄱阳湖湿地周边的交通状况决定, 本文以鄱阳湖周边国道干线为缓冲, 以距离长度划分标准,随距离 越大, 指数值越小.

(4) 水产养殖发展指数 (Fishery Industry Index, FII). 鄱阳湖区是江西省重要的渔业产区,作为湖区的核 心产业,需要合理开发、科学规划、可持续发展. 评价水产养殖发展指数由重要城市到鄱阳湖湿地的距离、经 济鱼类分布和湿地水域分布等情况决定.

(5) 饮用水源地重要性指数 (Water Resource Important Index, WRII). 鄱阳湖是周边地区主要水源地, 评价 鄱阳湖湿地的水源地重要性指数由重要城市到鄱阳湖湿地距离决定,在 $2 \mathrm{~km}$ 范围内为水源地极重要区, 按 等距离间隔划分不同标准,大于 $10 \mathrm{~km}$ 为一般重要区,表明作为水源地重要性最低.

表 2 鄱阳湖湿地生态系统服务功能重要性评价指标

Tab. 2 Indicators for ecosystem service function appraised in Lake Poyang wetlands

\begin{tabular}{|c|c|c|c|c|c|}
\hline 分级 & 极重要区 & 高度重要区 & 重要区 & 一般重要区 & 备注 \\
\hline 候鸟保护重要性指数 & 集中分布 & 一般分布 & 偶然分布 & 极少分布 & 候鸟出现的频率 \\
\hline $\begin{array}{l}\text { 鱼类资源保护重要 } \\
\text { 性指数 }\end{array}$ & $\begin{array}{l}\text { 保护鱼类和经济鱼类 } \\
\text { 出现区 }\end{array}$ & 保护鱼类分布区 & 经济鱼类分布区 & 无鱼类分布区 & \\
\hline $\begin{array}{l}\text { 旅游资源潜力指数 } \\
(\mathrm{km})\end{array}$ & $<2$ & $5-2$ & $10-5$ & $>10$ & $\begin{array}{l}\text { 以主要公路为 } \\
\text { 缓冲 }\end{array}$ \\
\hline 水产养殖发展指数 & 库塘区 & 湿地深水区 & 湿地浅水区 & 滩涂、裸地和岛屿 & \\
\hline $\begin{array}{l}\text { 饮用水源地重要性 } \\
\text { 指数 }(\mathrm{km})\end{array}$ & $<2$ & $2-5$ & $5-10$ & $>10$ & $\begin{array}{l}\text { 以主要城镇据 } \\
\text { 地缓冲 }\end{array}$ \\
\hline 分级赋值 (C) & 10 & 7 & 4 & 1 & \\
\hline
\end{tabular}

通过下面方法计算鄱阳湖湿地生态系统服务功能重要值:

$$
S D_{j}=5 \sqrt{\prod_{i=1}^{5} D_{i}}
$$

式中, $S D_{j}$ 为鄱阳湖湿地生态系统服务功能重要值, $D_{i}$ 为影响湿地生态系统服务功能重要性指标的等级值. 利 用地理信息系统软件中的空间叠加分析功能,把候鸟保护重要性指数、鱼类资源保护重要性指数、旅游资源 潜力指数、水产养殖发展指数、饮用水源地重要性指数 5 个单因子湿地生态系统服务功能的图层叠加,计算 每一个空间单元 $(10 \mathrm{~m} \times 10 \mathrm{~m}$ 栅格 $)$ 的湿地生态系统服务功能指数.

(3) 湿地生态功能重要性分区评价指标. 在分析湿地自然环境特征和湿地生态系统服务功能特征 的基础上,对两方面的评价结果进行综合评价,得出鄱阳湖湿地生态功能重要性分区评价结果. 计算 公式为:

$$
S I_{j}=S S_{j}+S D_{j}
$$

式中, $S I_{j}$ 为湿地生态功能重要性综合评价结果. 利用地理信息系统软件中的空间叠加分析功能,把湿地自然 环境和生态系统服务功能 2 个指标的图层叠加,计算每一个空间单元 $(10 \mathrm{~m} \times 10 \mathrm{~m}$ 栅格 $)$ 的湿地生态功能综 合评价指标,根据数值大小依次划分为极重要区、高度重要区、重要区和一般重要区(图 2).

\section{3 结果与讨论}

\section{1 鄱阳湖湿地边界的确定}

3.1 .1 鄱阳湖湿地边界确定的依据和原则 由于湖泊水位变化的季节性而导致湿地地理环境的复杂性, 鄱 
阳湖湿地边界一直没有得到确认. 本文在 Arc/Info 下, 利用鄱阳湖区 DEM 数据、数字化的湖区围堤数据配 准叠加, 参考《湿地公约》 ${ }^{[15]}$ 、《全国湿地资源调查技术规程 (试行)》(林湿发 [2008]265 号) ${ }^{[16]}$ 两个文件有 关湿地的定义内涵, 按照以下原则提取边界, 所得范围为鄱阳湖湿地.

(1) 多年平均最高水位原则. 这一原则主要是参考《全国湿地资源调查技术规程 (试行)》有关湿地范围 界定的要求提出的. 本文以星子水文站的多年平均最高水位作为依据, 星子站位于鄱阳湖中段, 水位受长江 和“五河”的影响较小.

(2) 典型性原则. 鄱阳湖湿地具有多种类型, 包括湖泊、河流和库塘; 景观类型则有水域、滩涂、草洲、沙 地,河流尾问、河流三角洲和湖中岛屿,这些景观是湿地的典型代表.

(3) 客观性原则. 通过利用高分辨影像 (SPOT) 再配合高精度 GPS 解译出人工堤坝. 天然堤坝主要是结 合 $1: 1$ 生成的 DEM、水文数据 (多年平均最高水位数据) 和高分辨影像 (SPOT) 人工目视解译自然堤坝 (主要 指由高山或小山丘组成).位于人工围堤和天然堤坝内区域都应该计人鄱阳湖湿地.

(4) 景观完整性和连通性. 在鄱阳湖周边有大大小小的人为拦截的湖泊, 有大坝将这些湖泊与鄱阳湖 分开, 但是他们与鄱阳湖在水量、能量和生物多样性方面相互关联, 相互影响. 这些湖泊与鄱阳湖在景观上 具有同质性,并且物质与能量具有连通性, 应该归为鄱阳湖湿地范围.

3.1 .2 鄱阳湖湿地范围 根据上述原则, 得出鄱阳湖湿地范围 (图 1), 其面积为 $3886 \mathrm{~km}^{2}$. 鄱阳湖湿地范 围涉及到湖口县、都昌县、鄱阳县、余干县、进贤县、南昌县、新建县、永修县、星子县、九江市等 10 个县市. 由于鄱阳湖湿地具有高度变化特征, 迄今为止, 各个部门、不同研究学科之间对鄱阳湖湿地范围没有比较 统一的认识和界定, 不同学科、不同部门往往根据自身的需要出发, 将鄱阳湖湿地界定为相应的范围. 例 如, 黄金国根据鄱阳湖湿地变化特征, 采用平均的湿地面积作为鄱阳湖湖区湿地面积范围, 为 $2698 \mathrm{~km}^{2[17]}$; 邬国锋等认为鄱阳湖湿地在枯水期、平水期和丰水期的面积分开计算为 $1290 \mathrm{~km}^{2}$ 、 $2797 \mathrm{~km}^{2}$ 和 $3900 \mathrm{~km}^{2[18]}$; 张本以 1989 年之前湖口水位站历年最高水位所淹没的范围计算湖区的湿地面积, 加上周边 湖汊, 划定鄱阳湖湿地面积为 $4646 \mathrm{~km}^{2[19]}$. 由此可见, 由于研究目标和参考依据不同, 湿地范围的结果也 不相同.

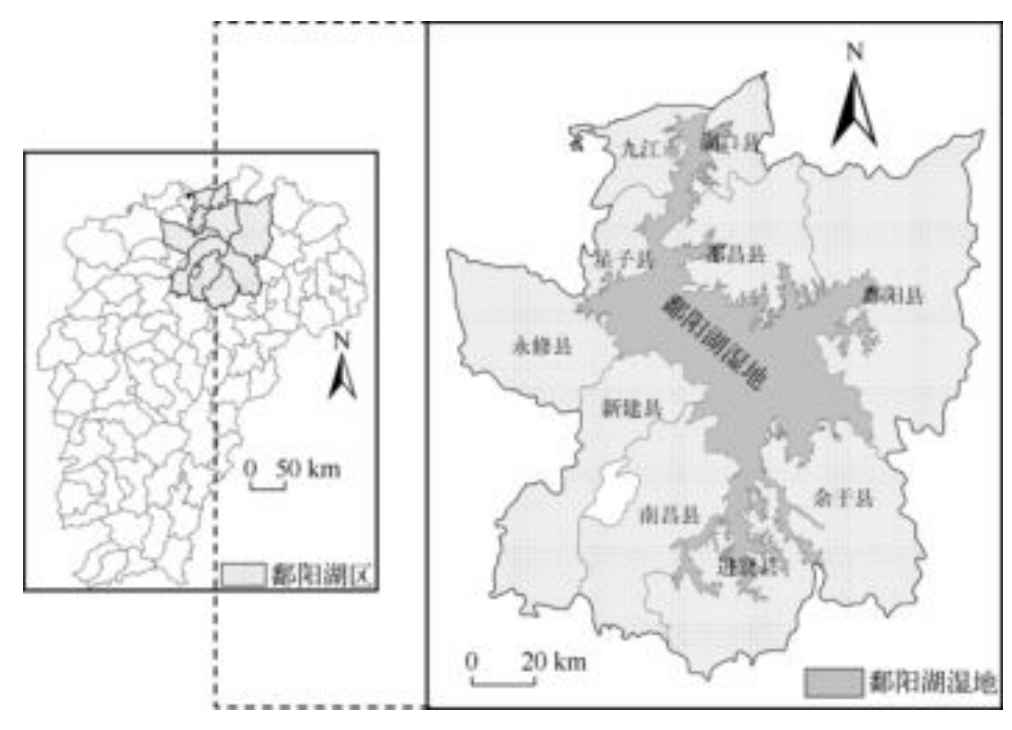

图 1 鄱阳湖湿地范围

Fig. 1 The range of Lake Poyang wetlands

\section{2 鄱阳湖湿地生态功能重要性分区评价结果}

通过叠加分析, $S I_{j}$ 值为 $2-13.7644$ 之间, 按照 $S I_{j}>10 、 7<S I_{j} \leqslant 10 、 4<S I_{j} \leqslant 7 、 S I_{j} \leqslant 4$ 进行重分类, 依次 
划分为极重要区、高度重要区、重要区和一般重要区,其面 积分别为 $125 \mathrm{~km}^{2} 、 1387 \mathrm{~km}^{2} 、 2064 \mathrm{~km}^{2}$ 和 $310 \mathrm{~km}^{2}$ (图 2).

极重要区在空间分布和数量上所占比例较小,但是在 自然环境和生态系统服务功能两个方面的重要性最为显 著, 是鄱阳湖湿地候鸟核心分布区, 特别是白鹤的主要繁 殖地, 也是鄱阳湖血吸虫主要防控区. 高度重要区在评价 等级值中仅次于极重要区, 在湿地自然环境和湿地生态系 统服务功能两个方面也都具有重要价值,特别是珍稀鱼类 的繁殖,主要分布在这个区域. 重要区空间分布和数量所 占比例较大, 是湿地水生植被主要分布的区域, 是各类候 鸟活动主要场所, 在生物多样性的保护方面具有重要作 用. 重要区也是湿地滩涂主要分布区域,在丰水期,这部分 区域常常被淹没,是蓄水调洪的重要区域.一般重要区主 要分布在湿地周边地带, 是人类活动较为频繁区和湿地退 化的潜在区, 在湿地保护和湿地生态安全维护方面具有重 要的作用.

\section{3 结论}

湿地的有效保护取决于具体行动. 湿地保护行动, 应 当立足于湿地现状和自然特征基础之上. 湿地生态功能重 要性分区研究,是明确湿地自然状况,有效评价湿地生态 系统服务功能价值的重要途径. 长期以来,由于各种因素 的限制, 鄱阳湖湿地范围不明确, 导致鄱阳湖湿地保护和 资源开发利用存在误区. 本文在分析湿地自然环境特征的

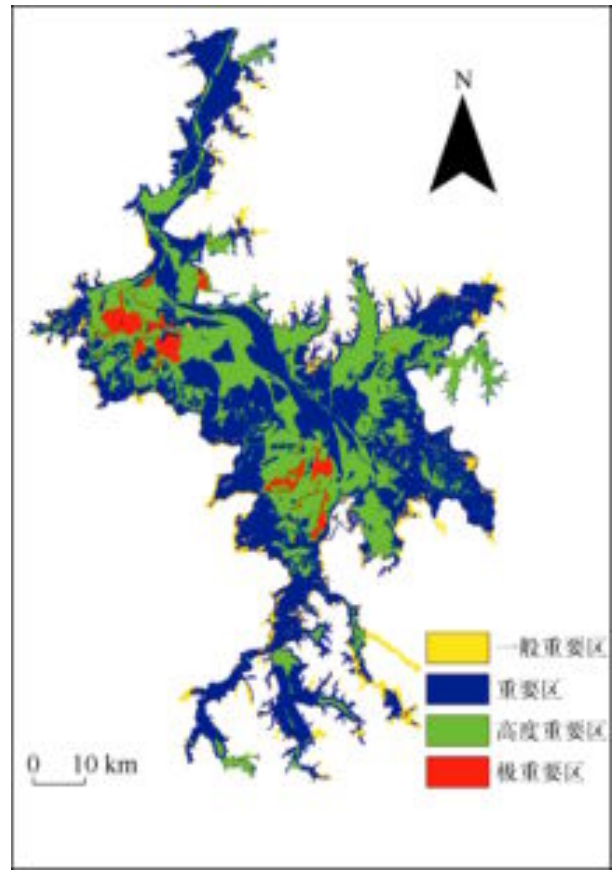

图 2 湿地生态功能重要性分区

Fig. 2 Map for eco-function importance zoning of wetlands

基础上,对湿地范围进行了界定, 提取的湿地面积为 $3886 \mathrm{~km}^{2}$. 通过分析湿地生态系统服务功能特征, 利用现 代地理信息系统技术,建立生态功能评价指标,对鄱阳湖湿地生态功能重要性分区进行了研究,得到鄱阳湖 湿地极重要区、高度重要区、重要区和一般重要区的面积分别为 $125 \mathrm{~km}^{2} 、 1387 \mathrm{~km}^{2} 、 2064 \mathrm{~km}^{2}$ 和 $310 \mathrm{~km}^{2}$.

根据《鄱阳湖生态经济区规划》 ${ }^{[20]}$, 本文界定的湿地范围位于规划的湖体核心保护区. 没有鄱阳湖湿地 良好的生态环境,就没有鄱阳湖生态经济区的战略规划. 基于鄱阳湖当前的现实基础,本文提出以下几条建 议. (1) 加强鄱阳湖湿地自然保护区的建设, 加强湿地保护与管理. 要保护湿地生态功能与生物多样性资 源; 控制水体养殖规模,防止水体富营养化; 稳定湖体水质,改善候鸟栖息环境. 对于极重要区和高度重要 区,面积为 $1512 \mathrm{~km}^{2}$, 都应该纳人国家自然保护区建设之中. 鄱阳湖湿地现有国家级保护区面积 $168.7 \mathrm{~km}^{2}$, 省级及以下级别的保护区面积 $615.7 \mathrm{~km}^{2}$, 省级及以下级别的保护区建设投人力度不够,应该全部纳人国家 级自然保护区的管辖范围之内. (2) 加强湿地保护的宣教工程建设,提高民众湿地保护意识. 在鄱阳湖周边 地区的部分居民,对于湿地的保护意识还不强, 布网捕鸟、投毒捕鸟的现象时有发生,这充分反映了居民在 湿地保护方面的意识仍然欠佳. (3) 加强鄱阳湖湿地科研与监测的投人,提高湿地生态安全保障水平. 鄱阳 湖水域开阔, 生态环境比较复杂, 在现有的水文水质监测站点基础上,增加站点和监测频率, 有利于实时全 面地掌握湿地生态环境的变化与特征. (4) 加强鄱阳湖湿地生态恢复与重建工程建设,提高湿地生态系统 服务功能. 1998 年特大洪水发生以后, 鄱阳湖湿地的生态系统服务功能的重要性得到了政府部门和社会的 高度重视, 治理鄱阳湖的投人力度也有所加大,特别是退田还湖工程, 使鄱阳湖湿地面积在近几年在一定程 度稳中有升. 然而, 鄱阳湖区是重要的产粮区, 人口众多, 湿地被侵占的压力仍然很大, 需要多方面的保障措 施, 才能确保鄱阳湖湿地免遭侵犯. 实施湿地生态恢复和重建工程,还原湿地的自然面貌, 确保鄱阳湖“一湖 清水”永续实现.

致谢: 感谢江西省遥感信息系统中心禁哲文主任、方豫副主任为本文提供的大力支持和乐兴华博士、黄灵光 硕士在论文撰写过程中给予的帮助;特别感谢评审专家提出的宝贵意见. 


\section{4 参考文献}

[ 1 ] Zhang XL, Zhang YZ, Sun HX et al. Changes of hydrological environment and their influences on coastal wetlands in the Southern Laizhou Bay, China. Environmental Monitoring and Assessment, 2006, 119: 97-106.

[ 2 ] Nielsen EM, Prince SD, Koeln GT. Wetlands change mapping for the U. S. Mid-Atlantic region using an outlier detection technique. Remote Sensing of Environment, 2008, 112: 4061-4074.

[3] 谭䀧霖. 鄱阳湖湿地生态环境遥感变化监测研究 [学位论文]. 北京: 中国科学院遥感应用研究所,2002: 1-2.

[ 4 ] Rowe JS. Land classification and ecosystem classification. Environmental Monitoring and Assessment, 1996, 39: 11-20.

[ 5 ] 鄢帮有. 鄱阳湖湿地生态系统服务功能价值评估. 资源科学, 2004, 26(3): 61-68.

[6] 谌贻庆, 甘䈗青. 鄱阳湖区国内旅游市场开发. 南昌大学学报 (理科版), 2004, 28(4): 405-408.

[ 7 ] 廖富强, 刘 影, 叶慕亚等. 鄱阳湖典型湿地生态环境脆弱性评价及压力分析. 长江流域资源与环境, 2008,17 (1) : 133-137.

[ 8 ] 荣冰凌,孙宇飞,邓红兵等. 流域水环境管理保护线与控制线及其规划方法. 生态学报, 2009, 29(2): 924-930.

[9]《鄱阳湖研究》编委会. 鄱阳湖研究. 上海: 上海科学技术出版社, 1988: 60-71.

[10］江西省水文局. 江西水系. 武汉: 长江出版社,2007: 90-91.

[11] 刘信中, 叶居新. 江西湿地. 北京: 中国林业出版社, 2000: 26-27.

[12] 王晓鸿, 鄢帮有, 吴国琛. 山江湖工程. 北京: 科学出版社, 2006: 7 .

[13] 禁哲文. 基于 GIS 的江西省生态脆弱性分析与评价研究 [学位论文]. 北京: 中国科学院地理科学与资源研究所, 2009: 83 .

[14] Kerry Turner R, van den Bergh JCJM, Soderqvist T et al. Ecological-economic analysis of wetlands: scientific integration for management and policy. Ecological Economics, 2007, 35 : 7-23.

[15] Convention on Wetlands of International Importance especially as Waterfowl Habitat. Ramsar, Iran, 2. 2. 1971, as amended by the Protocol of 3.12.1982, and the Amendments of 28.5.1987. http://www. ramsar. org/cda/en/ramsar-documents-texts/main/ramsar/1-31-38-4000-0(2010-06-12).

[16］国家林业局. 全国湿地资源调查技术规程(试行). 2008,12. http://www. docin. com/p-48879691. html(2010-06-12).

[17］黄金国. 洞庭湖区湿地退化现状及保护对策. 水土保持研究, 2005, 12(4): 261-263.

[18] 邬国锋, 崔丽娟, 纪伟涛. 基于时间序列 MODIS 影象的鄱阳湖丰水期悬浮泥沙浓度反演及变化. 湖泊科学, 2009, $21(2)$ : 288-297.

[19］张 本. 鄱阳湖自然资源及其特征. 自然资源学报, 1989, 4(4) : 308-318.

[20］国家发展与改革委员会. 鄱阳湖生态经济区规划. 2009,12. http://www. jx. xinhuanet. com/jxzw/2010-02/22/content-19070288. htm (2010-06-12). 